\title{
AIDS politics change rules
}

\section{San Francisco}

IN the next two or three months, the US Food and Drug Administration (FDA) is expected to begin review of two promising new AIDS drugs, the first such materials to be entered into the approvals procedure since AZT was approved four years ago.

This development will be a landmark test of procedures for the evaluation of new AIDS drugs. In the past few years, the worsening AIDS epidemic has brought unprecedented pressure on the FDA to approve new drugs more quickly. The FDA will now have a chance to show AIDS activists and others how quickly it can respond, but its handling of these two new compounds may also indicate how much AIDS has changed the politics of health care in the United States.

Both drugs - dideoxyinosine (ddI) and dideoxycytidine $(\mathrm{ddC})$ - have shown promise in clinical trials, but both can have serious side-effects. What constitutes adequate proof of their efficacy has never been completely defined by the health officials who will have to rule on them.

That imprecision, say advocates of the interests of AIDS patients, is delaying the process of gaining market approval for the treatments. And for the gravely ill, for whom the only approved AIDS drug, AZT, causes intolerable side-effects or is no longer effective, the delay, they say, costs lives.

The FDA will very soon have to face the issue of which criteria are acceptable for the evaluation of ddI and ddC. The manufacturers say they still have to complete some data analysis before they can file for FDA approval - a process that will take from weeks to months or more.

But even if the FDA received approval requests from the pharmaceutical companies today, it would be unable to respond, says David Barr, of the Gay Men's Health Crisis in New York, in the absence of established guidelines for the approval of AIDS antivirals. This "can only retard the development of new drugs", according to a formal petition filed with FDA last month by the Community Consortium, an association of 180 San Francisco Bay Area health-care providers who treat most of the people with human immunodeficiency virus (HIV) in the region.

Donald Abrams, professor at the University of California at San Francisco and chairman of the consortium, says that the FDA should also say what it looks for in the approval process to help defuse the current debate about the adequacy of the data available from the trials so far carried out.

Although they are expected to file for approval soon, both companies, BristoMyers Squibb, which makes ddI, and Hoffmann-La Roche, which makes ddC, want to carry out further tests that could take years. But activists say the data are already adequate and are imploring the companies to hurry their analysis and data submission.

Meanwhile, activists and some researchers hope that a turning point in the development of clear-cut guidelines will come on 13 February, when FDA's Antiviral Drugs Advisory Committee meets to discuss what endpoints or standards will be acceptable proof of efficacy. The Community Consortium, in its letter to FDA Commissioner David Kessler pressing for rapid approval of ddI and ddC, asserts that the government has authority to demand that the pharmaceutical companies should submit their current data by 1 February, and could resolve to decide the fate of ddI and ddC by 1 March. FDA has no comment yet on this point.

FDA's discussions will also be affected, and perhaps slowed, by the loss of Ellen Cooper, who resigned because of the pressure of work last month, after three years as the director of the Division of Antiviral Drug Products. Last week, the FDA announced that the position will be held temporarily by Carl Peck, Cooper's former superior, who directs the Center for Drug Evaluation and Research. Activists were widely disappointed at the departure of Cooper, whom they considered something of an ally within the administration.

Meanwhile, thousands of the estimated one million people in the United States infected with the AIDS virus are taking ddI or ddC through clinical trials and "expanded access" programmes. But activists say those procedures fall far short of the need. Expanded access, for example, makes promising drugs available only to patients for whom AZT's effectiveness has diminished or who cannot tolerate it, and excludes those who cannot afford a primary care physician or who do not meet specific health criteria whatever their physicians recommend.

Because it is considered unethical to use placebos in studies of people with the lifethreatening disease, data from controlled trials are not available, while the use as controls of patients from earlier studies is complicated by the changed treatment of AIDS over the years. Now, for example, pentamidine is widely used to treat the common opportunistic pneumonia, known as PCP, to which AIDS patients are prone, while the strains of HIV infecting patients have also evolved.

Studies therefore focus on comparisons of the effects of new drugs with those of AZT, which also raises complications.
Does it suffice for a drug to be as effective as AZT, or must it be better? Further complicating the picture is evidence indicating that ddl and ddC are most effective when they are used in combination with AZT.

Some argue that in the evaluation of new drugs, more reliance should be placed on their effects on biochemical features known as "surrogate markers" - the numbers of key immune cells in the patient's blood or the amounts of viral antigen present, for example. In AIDS, the most promising surrogate marker is widely thought to be the blood concentration of the immune cells known as CD4, which are the principal targets for attack by HIV.

The notion that increased concentrations of CD4 cells are an index of improved health is supported by most, but not all, studies so far carried out. But critics argue that CD 4 cells are an imprecise index of the health of the immune system, and may not indicate real cause-andeffect. Similar concerns have been raised about measurements of the p24 antigen of HIV, which reveals the level of actively replicating virus in the body.

Stanford University AIDS researcher Thomas Merigan believes that these surrogate markers would nevertheless be reliable in comparisons of the effects of ddI or ddC with those of AZT, on the grounds that all three drugs function by the same mechanism.

Deciding on the acceptability of surrogate markers is among the most crucial issues in AIDS politics today, says Mark Harrington of ACT UP, the AIDS Coalition to Unleash Power, in New York. Scientists and activists promise to watch closely the outcome for ddI and ddC, believing that the result may determine the fate of the new classes of AIDS pharmaceuticals on the horizon.

Elizabeth Schaefer

RESEARCH FOUNDATIONS

\section{First woman director for Wellcome}

\section{London}

BRIDGET Ogilvie is to be the next director of the Wellcome Trust, Britain's largest medical research charity, becoming the first woman to head the organization. She replaces Peter Williams, director since 1965, who retires at the end of September. Ogilvie was formerly a parasitologist at the Medical Research Council's National Institute for Medical Research in London.

The Wellcome Trust was set up in 1936 under the will of Sir Henry Wellcome, founder of the Burroughs Wellcome pharmaceutical company. The trust will this year spend $£ 78.7$ million on medical research and the study of the history of medicine.

PeterAldhous 